\title{
A Potência do Cuidado: uma Experiência no Sistema Prisional de Pernambuco
}

\author{
Antonio Lima ${ }^{1}$ \\ José Rodrigues de Alvarenga Filho ${ }^{2}$ \\ ${ }^{1}$ Instituto Aggeu Magalhães da Fundação Oswaldo \\ Cruz, PE, Brasil. \\ ${ }^{2}$ Universidade Federal de São João del-Rei, MG, Brasil.
}

Resumo: Nosso texto tem por alvo interrogar a dinâmica de funcionamento do sistema prisional de Pernambuco. Para tanto, utilizando a cartografia como estratégia metodológica e o ensaio como política narrativa, trabalhamos a construção do texto a partir de cenas analisadoras. Estas colocam em análise o cotidiano prisional e as forças que neste território atuam produzindo um cenário de violências, violações de direitos e vidas descartáveis. Por fim, sem a pretensão de apontar modos de atuar no sistema prisional, entendemos o cuidado como potente estratégia micropolítica de produção de resistências. Através de práticas de cuidado, apostamos em intervenções que, mesmo ao se darem em instituições que alimentam práticas que segregam, violentam e fabricam mortes, possam ensejar brechas para a emergência de processos de singularização a ventilar vidas, isto é, tornar possível a construção de linhas de fuga no modo de funcionar deste enorme "moinho de gastar gente" que é o sistema prisional brasileiro.

Palavras-chave: Prisão, Pernambuco, Cuidado, Apoio Institucional, Psicologia.

\section{The Potency of Care: an Experience in the Prision System of Pernambuco}

\begin{abstract}
Our text aims to interrogate the dynamics of the prison system in Pernambuco. For this, using cartography as a methodological strategy and the essay as narrative politics, we work on the construction of the text from analyzing scenes. These, analyze the daily prison and the forces that act in this territory producing a scene of violence, violations of rights and disposable lives. Finally, without the pretense of pointing to ways of acting in the prison system, we understand care as a potent micropolitical strategy for the production of resistances. Through care practices, we focus on interventions that, even when they occur in institutions that feed practices that segregate, violate and manufacture deaths, we can create loopholes for the emergence of singularization processes to ventilate lives, that is, to make possible the construction of escape routes in the way of functioning of this enormous "mill to spend people" that is the Brazilian prison system.
\end{abstract}

Keywords: Prison, Pernambuco, Care, Institutional Support, Psychology. 


\title{
La Potencia del Cuidado: una Experiencia en el Sistema Penitenciario de Pernambuco
}

\begin{abstract}
Resumen: Nuestro texto tiene por objetivo interrogar la dinámica de funcionamiento del sistema penitenciario de Pernambuco. Para ello, utilizando la cartografía como estrategia metodológica y el ensayo como política narrativa, trabajamos la construcción del texto a partir de escenas analizadoras. Estas, ponen en análisis el cotidiano prisional y las fuerzas que en este territorio actúan produciendo un escenario de violencias, violaciones de derechos y vidas desechables. Por último, sin la pretensión de apuntar modos de actuar en el sistema penitenciario, entendemos el cuidado como una potente estrategia micropolítica de producción de resistencias. A través de prácticas de cuidado apostamos en intervenciones que, aun al darse en instituciones que alimentan prácticas que segregan, violan y fabrican muertes, podamos dar brechas para la emergencia de procesos de singularización a ventilar vidas, es decir, hacer posible la construcción de líneas de fuga en el modo de funcionamiento de este enorme "molino de gastar gente" que es el sistema prisional brasileño.
\end{abstract}

Palabras clave: Prisión, Pernambuco, Cuidado, Apoyo Institucional, Psicología.

\section{Introdução}

Joguem fora a abstração e o aprendizado acadêmico, as regras, o mapa e o compasso. Sintam seu caminho sem anteparos. Para alcançar mais pessoas, deve-se evocar as realidades pessoais e sociais - não através da retórica, mas com sangue, pus e suor (Anzaldúa, 2000, p. 235).

Este artigo foi escrito a quatro mãos, conjugando diferentes geografias, temporalidades, trajetórias e experiências. A sua produção nos lançou a um exercício de estranhamento das forças instituídas e, ao mesmo tempo, de experimentação de outras formas de pensar; desafiando-nos a levantar questões sobre o sistema prisional brasileiro.

Nosso lugar de fala se faz num duplo movimento: na condição de pesquisador/professor, por um lado, e de psicólogo atuando como apoiador institucional $^{1}$ no sistema prisional de Pernambuco, por outro. Duplo movimento que se faz no agenciamento de um inconcluso "nós" que pôs em marcha, não sem excitações e tropeços, interrogações sobre a narrativa da experiência no sistema prisional e, ao mesmo tempo, a experiência da narrativa num tempo, como apontam Agamben (2005) e Bondía (2002), condenado à impossibilidade da experiência e reduzido às narrativas que são apenas informação e opinião. A partir da obra de Foucault (2010, p. 289), entendemos que "uma experiência é qualquer coisa do qual se sai transformado". A experiência enquanto acontecimento nos interpela e nos lança em diferentes processos de subjetivação². Ao mesmo tempo, compreendemos a experiência de pesquisar/intervir enquanto descaminho daquele que pesquisa/intervém. Como aponta Foucault (1998, p. 13), "de que valeria a obstinação do saber se ele assegurasse apenas a aquisição dos conhecimentos e não, de certa maneira, e tanto quanto possível, o descaminho daquele que conhece?". Na perspectiva tradicional, pesquisar é se distanciar das dúvidas, das incertezas e, a partir do imperativo da razão, trilhar um caminho iluminado e seguro que nos possa

\footnotetext{
${ }^{1} \mathrm{O}$ apoiador institucional é o que desempenha a função do Apoio Institucional. A concepção deste dispositivo, traçado na Política Nacional de Humanização (PNH) do Sistema Único de Saúde (SUS), teve grande colaboração de pesquisadores do campo da Psicologia. O apoio institucional "implica em uma ação 'entre', na interface entre produção de saúde e produção de subjetividades” (Passos, Neves, Benevides, 2006 apud Brasil, 2010, p. 21). O que move o trabalho do apoiador institucional é acompanhar movimentos, auxiliando a reflexão e análise dos coletivos, de forma democrática, com alvo a produzir novas formas na atenção ao cuidado e na gestão do SUS.

${ }^{2}$ A partir das contribuições de Guattari e Rolnik (1996), entendemos a produção de subjetividade como a construção de modos de existir. Tais modos, longe de se referirem a uma essência, concernem a uma multiplicidade de agenciamentos e atravessamentos que ensejam diferentes maneiras de experimentar a vida.
} 
levar ao desvelamento da natureza, à descoberta de suas verdades. Em Foucault, o ethos da pesquisa não implica na busca por certezas, mas em experimentações que nos levem para longe de nós mesmos. Deste nós que não é uma essência fechada, mas inconclusos movimentos que acontecem e nos encontros e passagens da vida vão se destruindo e construindo.

Nesta escrita singular ${ }^{3}$ não há neutralidades ou cômodo distanciamento, mas sim a revolta diante de tecnologias de poder que tornam vidas descartáveis e sujeitas aos dispositivos genocidas como o sistema prisional e a segurança pública brasileira por meio de suas táticas de confinamento, repressão e extermínio. Tais dispositivos precisam ser legitimados e, para tanto, convocam disciplinas da norma (Prado Filho, \& Trisotto, 2007), o que inclui a Psicologia. Como mostra Coimbra (1995), a ditadura civil-militar é um funesto exemplo de como diferentes práticas psi se tornaram "guardiãs da ordem". O que nos move, também, é a aposta de transformarmos nossos escritos e pesquisas, em "máquinas de guerra" a produzirem arranhões, fissuras, ou seja, brechas no modo de funcionamento instituído e do qual todos nós, em intensidades e papéis distintos, fazemos parte. Inspirados em Nietzsche (2017), tentamos fazer de nossas teorias/práticas martelos a quebrar os instituídos e fazer aparecer, onde existe apaziguada naturalização e/ou essência, os jogos de forças a compor o mundo e a nos compor.

Metodologicamente, construímos nosso texto a partir de fragmentos ${ }^{4}$ de experiências vividas - chamadas aqui de "cenas" - por um dos autores, com formação em Psicologia, que atuou como apoiador institucional no sistema prisional de Pernambuco. À luz das contribuições da Análise Institucional (Altoé, 2004; Lourau, 1993), podemos pensar tais cenas como analisadores das dinâmicas dos poderes (instituídos e instituintes) que atravessam e compõem a instituição prisão. As experiências aqui narradas foram registradas em diário de campo e (re)trabalhadas neste artigo. Definiu-se como prisma a híbrida perspectiva cartográfica, que consiste em acompanhar processos de um dado território. Entendemos o território não somente como mapas estáticos e estatísticos, mas sim como espaços político-existenciais, de relações de poder, de vínculos e afetos. A cartografia vale-se da tentativa - pois trata-se de uma aposta política - da reversão dos métodos tradicionais ao afirmar que o caminho é o que determina as metas e não o contrário (Alvarez, \& Passos, 2009). O exercício da cartografia implica em estar imerso num território, tendo como pista metodológica permitir ser afetado pelo mesmo, pois para o cartógrafo "não há nada em cima - céus da transcendência -, nem embaixo - brumas da essência. O que há [...] por todos os lados são intensidades buscando expressão" (Rolnik, 1989, p. 2).

Ao adotarmos a perspectiva cartográfica, e entendendo-a como subversiva, interessa-nos num relato ensaístico ${ }^{5}$ "dar passagem, fazer passagem, ser passagem [...]", pois “[...] toda cartografia é um conhecer-fazendo" (Costa, 2014, p. 75). É preciso estar atento à dinâmica das forças que compõe o território, assim como, ter curiosidade e estar disponível à experimentação das experiências e suas intensidades. Se a transitoriedade e a provisoriedade são aspectos dos processos de construção e desconstrução da realidade, sempre inacabada, mais do que retratar e/ou representar, a cartografia implica em acompanhar processos em territórios que são inconclusas passagens e que ensejam inusitados e inesperados encontros. Neste contexto, é necessário nutrir uma atenção flutuante (Costa, Angeli, \& Fonseca, 2009). Por outro lado, a prisão impõe limites ao exercício cartográfico na medida que a circulação dos corpos por seu território, bem como as possibilidades de diálogos, são alvos de um grande controle. Todavia, o diário de campo apresenta-se como importante dispositivo para o trabalho cartográfico na prisão, funcionando como "uma tela impressionista onde podemos colocar aquilo que parece não caber na alma" (Leite, 2014, p. 805).

\footnotetext{
${ }^{3}$ Como afirma Fonseca, Kirst, Oliveira, D’Ávila e Marsilac. (2006, p. 656), “a partir do momento em que nos atrevemos a escrever de forma singular, é possível trazermos a público a experiência de afecção. A referida afecção faz nascer um espetáculo e com ele a contaminação e o entusiasmo por mais sabermos daquilo em que diferimos e daqueles que nos acompanham".

${ }^{4} \mathrm{~A}$ escrita em fragmentos subverte o modo vigente de uma razão iluminada presente em muitos textos acadêmicos, em "escritas assépticas tristes" (Machado, 2004, p. 147).

${ }^{5}$ Ao seguirmos as trilhas de Foucault (1998, p. 13), compreendemos o ensaio como "experiência modificadora de si no jogo da verdade". Isto é, o ensaio como um exercício de "ascese" no pensamento. Como aponta Bondía (2003, p. 111), sobre a construção ensaística, "o ensaio é fragmentário, parcial e seleciona fragmentos como sua matéria. O ensaísta seleciona um corpus, uma citação, um acontecimento, uma paisagem, uma sensação, algo que lhe parece expressivo e sintomático, e a isso dá uma grande expressividade".
} 
Interrogamos a experiência vivida compondo-a com as ferramentas teóricas de um "elenco de pensadores libertários" (Batista, 2017, p. 5). Almejamos fazer um "diagnóstico do presente" que consiste em, a partir de alguns pontos que o olhar designou, bem como da nossa relação com as experiências da atualidade, "diagnosticar as forças que constituem nossa realidade e que ainda a movimentam" (Artières, 2004, p. 16).

Assim, pensamos uma "metodologia-canteiro-de-obras ${ }^{6 "}$, composta por fragmentos, interrogações, retalhos, dúvidas, leituras e escritas. Uma metodologia interessada em construir outras políticas narrativas no âmbito da produção acadêmica ${ }^{7}$. Nossa escrita traz em suas linhas, como diz a epígrafe, "sangue, suor e pus" e aposta na produção de narrativas transgressoras (Bondía, 2003). Afinal, como aponta Alvarenga Filho (2010, p. 17), "aprendemos a usar as teorias e as artes como armas e a fazer de nossa escrita um exercício de liberdade, nunca de submissão [...]. Escrever é, sobretudo, um trabalho ético.".

\section{Números do sistema prisional brasileiro e as singularidades do "Leão do Norte"}

No que concerne ao sistema prisional brasileiro, de acordo com o Levantamento Nacional de Informações Penitenciárias (Infopen) do Departamento Penitenciário Nacional, atualmente vinculado ao Ministério Extraordinário da Segurança Pública (Depen/Mesp), o Brasil possuía até 2014 cerca de 622.202 pessoas presas. Os novos números do Infopen divulgados no final de 2017 mostram um incremento de $16,79 \%$, alterando a posição do país de $4^{\text {a }}$ para $3^{\text {a }}$ no ranking mundial. São 726.712 pessoas privadas de liberdade, até o mês de junho de 2016, para 368.049 vagas. A população privada de liberdade (PPL) é hoje composta por 665.482 homens e 42.355 mulheres, o que representa, res- pectivamente, $91,57 \%$ e $5,82 \%$. Além de ser majoritariamente composta por homens, a PPL brasileira é formada por jovens entre 18 a 29 anos (55\%), solteiros $(60 \%)$, de baixa escolaridade sem ao menos ter acessado o ensino médio (75\%) e, em sua maioria, por negros - pretos e pardos - (64\%). Enquanto a população geral brasileira aumentou cerca de 40,36\% em 25 anos, a PPL do país cresceu vertiginosamente: 707\% (Brasil, 2017).

Do mesmo modo, o estado de Pernambuco também apresenta números consideráveis e maiores do que os percentuais nacionais. Sua PPL, a $6^{\text {a }}$ maior do país, aumentou de 2014 até junho de 2016 mais de $28,00 \%$ e tem hoje 32.884 homens e 1.672 mulheres, o que perfaz $95,16 \%$ e $4,84 \%$, respectivamente, custodiada nos 79 equipamentos penais ${ }^{8}$ do estado. As características desta população acompanham a realidade nacional, exceto com relação ao percentual de solteiros (43\%), com $61 \%$ formada por jovens entre 18 a 29 anos, mais de $84 \%$ que não acessou o ensino médio e $83 \%$ composta por negros. Pernambuco também se destaca por ter em sua PPL o maior percentual de pessoas analfabetas, a saber, 19\%. Das 22 unidades prisionais ${ }^{9}$ voltadas para o cumprimento da pena em regime fechado, classificadas como presídios ou penitenciárias, as seis com o maior número de pessoas custodiadas estão localizadas na região metropolitana do Recife, totalizando em torno de 13.569 pessoas, número este que representa $39 \%$ da PPL do estado. Somente o Complexo Prisional do Curado (CPC), antigo Presídio Professor Anibal Bruno, localizado na zona oeste do Recife, possui aproximadamente sete mil homens privados de liberdade. No ano de 2011 foram feitas denúncias à Comissão Interamericana de Direitos Humanos (CIDH) da Organização dos Estados Americanos (OEA) das graves violações de direitos no então Presídio Professor Anibal Bruno, conforme trecho da carta-denúncia:

\footnotetext{
${ }^{6}$ Na publicação “Michel Foucault”, Artières, Bert, Gros e Revel. (2011, p. 4), investigando as estratégias de trabalho de Michel Foucault, apontam que "o pensamento não é uma coisa abstrata; que ele se realiza no quotidiano da pesquisa, das trocas e das discussões; que ele é feito de retalhos, de fragmentos, de pequenos trechos, de hipóteses, de pistas seguidas ou abandonadas, de empréstimos, de contatos, de discussões - em resumo, que ele é um canteiro, um trabalho".

${ }^{7}$ Como afirma Alvarenga Filho (2017, p. 36), não pretendemos "menosprezar a escrita acadêmica 'tradicional', mas é preciso que afirmemos outras políticas de narrativa onde possamos contar as histórias que estamos dispostos a esquecer”.

${ }^{8}$ De acordo com a Lei no 7.210 de 11 de julho de 1984, a ainda vigente Lei de Execuções Penais (LEP), o Sistema Prisional engloba os equipamentos penais: Penitenciárias; Colônias Agrícolas, Industriais ou Similares; Casas de Albergados; Centros de Observação; Hospitais de Custódia e Tratamento Psiquiátrico; e Cadeias Públicas.

${ }^{9}$ Está em curso a construção de mais um complexo prisional em Pernambuco - denominado Centro Integrado de Ressocialização (CIR) - em Itaquitinga, município da região da zona da mata do estado. O CIR terá cinco unidades prisionais, inclusive uma penitenciária federal. Notícia recuperada de: http://www.sjdh.pe.gov.br/node/1384.
} 
encontramos vários presos com relatos e lesões de tortura; alguns funcionários de saúde confirmaram que lesões graves, como aquelas produzidas por facadas, eram comuns no Aníbal Bruno. Também conversamos com chaveiros, um dos quais estava abertamente armado com um facão; outro chaveiro nos confessou que havia deixado 3 (três) presos no pavilhão sob seu controle serem espancados para 'manter a disciplina'. [...] Em agosto e setembro de 2010, visitamos o Pavilhão S ("Saúde"), direcionado aos presos com doenças graves e infectocontagiosas, que reunia dezenas de presos com doenças gravíssimas sem qualquer atendimento regular [...] Também encontramos outros vários internos com ossos quebrados que imploravam por remédios simples para dor [...] Presos com ferimentos visíveis e doenças graves passam meses no pavilhão sem receber qualquer tratamento. [...] Todos esses casos [...] foram apresentados por ofício com pedido de providências para as autoridades estaduais competentes, [...] mas não obtivemos resposta. ${ }^{10}$

Em abril de 2014, após o descumprimento de muitas das recomendações da CIDH, o Brasil foi condenado pela Corte Interamericana de Direitos Humanos (CorteIDH) da OEA por conta das violações ocorridas no referido presídio. Isto mostra que o sistema prisional pernambucano não é um sistema qualquer. O estado, conhecido como o Leão do Norte devido ao histórico espírito combativo de seu povo na Revolução Pernambucana ocorrida em 1817, numa época em que havia somente sul ou norte na divisão territorial do país, possui ainda hoje um dos piores sistemas prisionais das Américas. Face a isso, a escassez de trabalhos que discutam este peculiar território mostra a relevância deste texto ensaístico a partir de suas cenas, com o objetivo de "[...] dizer bem alto que a injustiça dói” ${ }^{11}$ e que é preciso falar das possibilidades e dos limites deste dispositivo tão nefasto que é a prisão, em especial sua forma de operar em Pernambuco.

\section{Cena 1: Pele negra, olhares brancos ${ }^{12}$}

Um novo dia de trabalho começa ainda no ônibus, quando me desloco para a unidade prisional para atuar como apoiador institucional. O trabalho do apoiador institucional nunca é isolado. Não é possível afirmar um "eu", uma instância celular, independente. Para desempenhar o apoio institucional é preciso compreendê-lo como um constante "nós", ou seja, como um dispositivo alicerçado no coletivo. E não é fácil ser apoiador institucional num presídio. Inicialmente, fui confundido como um espião do gestor, como mais um para dar ordens ou trazer ideias mirabolantes que não levavam em consideração a realidade do estabelecimento penal, dos sujeitos e sua complexa trama de relações de poder. A formação em Psicologia foi crucial para lidar com esse desafio, pois entendia que ser apoiador institucional não era apoiar a instituição, isto é, obedecer às normas e padronizar condutas por meio de uma postura verticalizada e que não reconhecesse a autonomia, a vez e a voz dos sujeitos. Antes de tudo, pautado na Análise Institucional, precisei resgatar o que é instituição, entendendo-a como lógicas, formas sociais que engendram e atravessam a sociedade (Baremblitt, 2002). Portanto, não visava ser o profissional preocupado com a manutenção do presídio, mas sim em ser um "fora dentro incluído" (Benevides, 2013, p. 275) interessado em estratégias de desmonte da instituição prisão a partir de uma aposta na capacidade construída de análise e autonomia do coletivo - representado ali pelos profissionais e pelos privados de liberdade para inventar outras formas de produção de saúde e de cuidado, algo possível por meio da circulação de afetos, da troca mútua e do estabelecimento de vínculo. Indagava-me quase sempre sobre o termo apoiador institucional. Enxergava-me como um "apoia-dor", aquele que apoiava a dor, ou as dores provenientes daquele estabelecimento tão nocivo.

No meio do caminho, além das pedras de Drummond (2010), a polícia. A mesma entra na condução e o único a ser revistado sob os olhares inquisidores de todos, sob as armas apontadas e suas fardas,

\footnotetext{
${ }^{10}$ Recuperado de: http://arquivoanibal.weebly.com/uploads/4/7/4/9/47496497/01_solicitacao-de-medidas-cautelares-presidio-anibal-bruno-final-2011-06-03_--pub.pdf

${ }^{11}$ Trecho da canção Madeira que cupim não rói, frevo de bloco carnavalesco composto por Capiba na década de 1960. A canção é hoje considerada por muitos o segundo hino do estado de Pernambuco.

${ }^{12}$ Fazemos referência ao livro Pele negra, máscaras brancas (Fanon, 2008).
} 
somos nós - as pessoas de pele preta. Nós que fazemos parte do grupo social que é historicamente criminalizado e encarcerado no Brasil; nós que, apenas por estarmos ali, sofremos a intervenção das forças repressivas. Estas, em nome da suposta segurança da sociedade, e carregando em si um racismo institucional secular, nos olha como ameaça. Pior, como alvo a ser abatido.

$\mathrm{Eu}$, um corpo preto, fui o único revistado. Em meio à revista, houve selfies, sorrisos, e pedidos de um passageiro para filmar a abordagem policial. "Vocês estão de parabéns", ele disse. Sob aplausos daquela população, provavelmente oriunda das periferias do Recife, os policiais desceram do coletivo. O ônibus seguiu e, novamente abordado, agora por um homem branco que me dizia: "Puxa, negão. É complicado, não é mesmo? Esses caras só revistam pessoas de cor. Olha eu aqui com a minha cerveja. E também tô 'chapado' e ninguém fez nada comigo porque sou branco, eu sei disso. Desculpa aí".

Como nos conta Santos (2004), a associação entre pobreza e negritude é recente na história do Brasil, emergindo a partir de 1888 com a abolição da escravatura. Momento em que os negros recém-libertos "ascenderam" à condição de pobres e o "mundo da pobreza" se escureceu. No contexto da abordagem policial descrita, os demais passageiros, parafraseando Joel Rufino dos Santos, tiraram partido da única vantagem que tinham: não eram negros.

Ao chegar na unidade prisional, percebo que a dinâmica dos olhares dos agentes penitenciários é similar à dos policiais naquele transporte público: um mirar intenso, quase que de perseguição do corpo negro. Do meu corpo. A intensidade do olhar é apaziguada quando o trabalhador negro coloca o seu jaleco branco. Revestido do suposto poder do jaleco branco, adentro à parte do presídio onde lá estão os "pretos... e outros quase brancos, mas tratados como pretos", como diz a canção Haiti, de Caetano Veloso e Gilberto Gil.

Nos perguntamos, tal como Augusto (2010), se "estamos todos presos". Se tanto faz estarmos numa unidade prisional ou num coletivo, para nossos corpos se tornem alvos de olhares que perseguem, julgam, condenam; de gestos sutis, mas cruéis, de indiferença e cumplicidades diante de violências. Num breve, porém forte texto, Tamis (2018) descreve o seu encontro com um jovem sendo quase linchado por populares em São Paulo. Ela intervém, e percebe que a polícia já estava ali antes mesmo de chegar. Os anônimos desejosos de "fazer justiça com as próprias mãos", de vingar-se do suposto jovem batedor de carteiras, já trazia em si, em seu processo de subjetivação, as fardas e o olhar de quem, diante dos corpos impertinentes, só reflete o brilho opaco do clamor punitivo. Há fardas por todos os lados.

\section{Cena 2: "Doutor, eu só quero ir lá para fora"}

Sexta-feira, dia de entrega dos medicamentos e orientações gerais, além de ser o dia das consultas psiquiátricas. Os processos de medicalização da vida entram em cena para, em nome da saúde dos presos, promover, em muitos casos, o controle bioquímico do viver. Certa vez, um dos psiquiatras disse que sua função era medicar os presos para conter os ânimos dos mesmos, garantindo, assim, a manutenção de uma suposta paz da cadeia, sem brigas, sem rebeliões. É através da medicação que corpos irrequietos são apaziguados e bem digeridos pela instituição. Entram em ação as drogas da obediência (Decotteli, Bohre, \& Bicalho, 2013).

$\mathrm{Na}$ manhã daquela turbulenta sexta-feira, um novo jovem preto entrou na unidade prisional. Novos olhares sobre aquele corpo, sob sua ancestralidade escrava, também aprisionada e feita vida descartável. A prisão atualiza a lógica escravocrata na medida em que com os seus feitores do mato (profissionais da vigilância e saúde) e seus pelourinhos (as torturas e privações) submete principalmente os corpos pretos a um regime de exceção.

Aquele jovem, "'a carne mais barata do mercado", é mais um custodiado pelo Estado pelo crime de tráfico de drogas. Este, que os criminalistas (Valois, 2016) denominam o grande vetor de criminalização dos pobres. Em meio aos demais privados de liberdade e profissionais de jaleco branco, seu olhar pedia ajuda. Nesse sentido, o cuidado em saúde envolve não só a procura daquela pessoa que o demanda, mas também a disponibilidade daquele que pode oferecê-lo. Logo, o olhar atento e a sensibilidade são características para que haja acolhimento. E foi assim que o jovem atordoado chegou.

Seu ímpeto foi se dirigir à sala de curativos, talvez um espaço material e, sobretudo, simbólico de lugar de cuidado. Segui o jovem. Ele se sentou no chão e começou a chorar, tampando os ouvidos com as mãos e dizendo: "Eles querem me matar. São muitas 
vozes. Eu não aguento mais. Eu tenho que sair daqui. Me ajuda, doutor!". Busquei entender melhor sua história e chamei os colegas da equipe e entendemos que caberia a consulta com o psiquiatra.

Na semana seguinte, esse mesmo jovem fez um profissional de refém, com o intuito de materializar o seu desejo: sair daquele espaço violador, tão destrutivo para a sua saúde mental. E ele foi contido com um tiro na perna e outro no abdômen. Logo depois, o jovem foi encaminhado para o Hospital do território para a realização de cirurgias. Tal experiência me fez pensar como o contexto prisional viola direitos não somente dos custodiados pelo Estado, mas também dos próprios profissionais. Estamos todos presos!

Os encontros no cotidiano prisional produzem, em nós, inúmeros afetos. No plano do sensível, nos sentimos tocados e, muitas vezes, exauridos. É preciso criar um corpo para habitar este espaço. Um corpo que não sucumba simplesmente àquelas forças destruidoras da vida, mas que possa, em seu engajamento naquele território de violências, potencializar brechas e linhas de fuga. Entendemos que a formação em Psicologia pode tanto fabricar "escutas surdas" (Baptista, 2001), pouco sensíveis às lutas por direitos humanos, com profissionais que se dizem "neutros", como nos oferecer ferramentas para nos afetarmos e experimentarmos intervir de maneira a, mesmo diante da morte, potencializar a vida.

\section{Cena 3: "Cabra safado. Tem que ser preso e aprender a ser homem direito"}

Estava acompanhando a equipe de saúde na tarefa de reavaliação de casos. Naquele dia, a equipe era formada por uma enfermeira, uma técnica de enfermagem e uma assistente social. Numa das celas, antes mesmo da entrada, estranhei o burburinho atípico. Vozes exaltadas e até gritos podiam ser ouvidos. Parecia que assistam uma partida de futebol na pequena televisão daquele espaço. Para o meu total espanto, o entretenimento do dia era um programa policialesco local, desses que trabalham com a lógica jornalística sensacionalista do "espreme-que-sai-sangue". Como diz Batista (2003), a imprensa legitima o poder punitivo exercido pela ordem burguesa. Mais do que comunicar, a mídia tornar-se um aparato do poder de punir.

Dentro da cela, os privados de liberdade assistiam e aplaudiam mais um caso trivial desse tipo de jornalismo: a apreensão de drogas que decretou a prisão de um jovem negro morador da periferia da região metropolitana do Recife. Diziam: "Isso mesmo. Cabra safado. Tem que ser preso e aprender a ser homem direito". De repente, aquela cela insalubre, com aqueles corpos reduzidos à sobrevida, tornou-se um estranho tribunal onde cada um, na condição de acusador e julgador, julgava e condenava, com certa dose de desavergonhada alegria, um jovem tão preto e tão pobre como eles. Num mundo acostumado com o imperativo do julgamento e da sentença, a lógica inquisitorial do tribunal, como aponta Augusto (2010), passa a habitar as condutas de cada um.

O tribunal se instala para o enquadre de um outro, possível transgressor que deve aceitar ser governado. O governo das condutas na sociedade disciplinar passa, como mostra Foucault (2008), pelo controle biopolítico dos corpos. Neste contexto, os privados de liberdade, apesar de terem passado por diferentes tribunais e tipos de castigos e privações na prisão, diante de um outro que será condenado a mesma trajetória, vindo de território semelhante, mais do que solidarizar-se, o que se vê é alegria e comemoração.

E assim todos aqueles privados de liberdade comemoravam o encarceramento de mais um jovem, pobre e negro. Mais um a fazer girar este macabro "moinho de gastar gente" (Ribeiro, 2015) com o seu funcionamento funesto condenando vidas ao descarte e à reclusão. Diante daquela mórbida comemoração, a minha única atitude foi me colocar propositalmente próximo ao aparelho de TV e, com os braços cruzados, olhar atentamente com um semblante sério para todos os que estavam no recinto. Bastou poucos segundos para o fim daquela euforia, quase uma histeria coletiva. "Pelo jeito vocês estão todos bem”, disse a eles. Pouquíssimas palavras. A intervenção se dava na intensidade do olhar. Cabisbaixos, alguns diziam que estavam assistindo porque o crime ocorrera justamente em seus bairros de origem, na região onde nasceram e foram criados. Um outro disse: “É, doutor. A gente aqui preso, largado e aí vem esse moleque novo e faz uma coisa dessas. Vai ficar lascado igual a gente!". Na busca por uma análise das minhas implicações, entendia que o olhar é um tanto constrangedor às vezes, mas foi uma intervenção, uma experimentação. Eu estava num território, naquela cela-enfermaria, próximo a eles e disposto a produzir algum tipo de reflexão através da intensidade do olhar 
e dos braços cruzados, que ali representavam não uma altivez, mas uma forma de dizer que estávamos presos à lógica punitiva.

Não era só da vida do mais recém-ingresso ao sistema prisional que aqueles homens falavam. Eles tinham interesse também naquele território. Nos lugares onde suas trajetórias foram construídas. A única forma de ver o seu território, a sua pátria pobre representada. E assim entendi que a lógica punitiva é como um manto que nos cobre, deixando-nos cegos e não protegidos, ou então como uma rede de pesca que, mesmo vazada e possibilitando enxergar o que está a nossa volta, nos paralisa, tornando-nos reféns de um caçador voraz, multifacetado e (in)visível. E essa é uma das perversidades do sistema: colocar os punidos e mal pagos (Batista, 1990) uns contra os outros. Fim do expediente. Muitos permaneceram na enfermaria. Uns retornaram aos seus pavilhões, para mais uma vez entrar no inevitável "rodízio"13. As periferias são as águas utilizadas para fazer continuar girando este "moinho de gastar gente". Dentro da prisão, todos nós nos tornamos peças descartáveis deste moinho.

Contudo, entendemos que se escolhemos no "moinho" entrar - seja no sistema prisional ou em outros "moinhos" de intensidades diferentes, como a Universidade, onde corpos também são gastos - não foi para meramente fazermos suas pás girarem. Pelo contrário, tomamos nossa implicação em tais instituições como estratégias micropolíticas produtoras de possíveis desvios nos modos de funcionamentos instituídos.

No simbolismo do cavalo de Troia algo é ofertado, mas cujos objetivos escapam da percepção daquele que recebe o "presente". Este, depois de dentro da fortaleza, se faz artefato de luta para a produção de intervenção. Uma "Psicologia cavalo de Troia" é convocada a fazer os moinhos de gastar gente girarem cada vez mais rápidos e genocidas, mas cabe ao "psicólogo-troiano" montar artefatos de luta e produzir intervenções-desvios.

\section{Cena 4: "Pega a sua mochila e vai embora, doutor. A cadeia vai virar"}

Muitas vezes a cadeia estava prestes a ter algum motim, a "virar", como dizem, e os concessionados - privados de liberdade que nos auxiliavam nas atividades - entravam na sala e diziam: "Doutor, pega as suas coisas e vai embora”. E eu, buscando entender, retrucava: "Mas o que houve?"; "Pega a sua mochila e vai embora, doutor. A cadeia virar. Vai agora. AGORA, doutor". E, no susto, sem mais questionar, obedecia à fala imperativa, saindo do local, quase sempre escoltado pelos privados de liberdade. O coração ficava em frangalhos, os afetos à flor da pele, pois eu tinha a oportunidade de sair, mas aqueles jovens não. Atordoava-me não saber o que poderia acontecer e se os encontraria vivos no dia seguinte.

Com isso, compreendia que o ato de cuidado é realmente paradoxal, como afirma Merhy (2004), pois tanto pode aprisionar quanto liberar. Entendia ali a fluidez entre cuidar e ser cuidado. Lugares distintos e que se misturam. Ocupados e cambiados a partir de uma determinada cena. Eu, um profissional de saúde habituado a pensar o cuidado dos outros, também era alguém que recebia o cuidado daqueles privados de liberdade. Era o resultado do vínculo, do respeito às suas vidas, construído cotidianamente.

Naquela mesma semana a acolhida aos internos foi interrompida quando vários presos chegaram à sala de procedimentos feridos por arma branca. Sangue nos corredores e semblantes de dor. Era o momento de interromper a fala destinada aos novatos para tratar das feridas abertas nos "antigos moradores". Tudo aquilo me trazia à memória um recente episódio de quando um privado de liberdade foi esfaqueado e já não era possível fazer mais nada. Seu corpo já estava tingido de sangue, uma cor rubra que quase encobriu sua cútis negra, um corpo que horas depois morreria na emergência do hospital geral.

Que corpo é esse que o sistema prisional "devolve" para a sociedade? Que corpo produz? Um corpo despotencializado. Um corpo estigmatizado. Um corpo morto. E parece que é isso que a ilusória "ressocialização" visa: devolver homens e mulheres para o convívio social, ainda que seja debaixo de sete palmos, no caixão. Estas "vidas que ninguém vê" (Brum, 2006), inúmeras vezes se rebelam, insurgem, e com a violência do Estado e o apoio de parcela da sociedade são

\footnotetext{
${ }^{13} \mathrm{O}$ rodízio a que nos referimos se trata da prática, construída entre os privados de liberdade em Pernambuco, que visa diminuir a lotação das celas através da produção de corpos machucados. Isto é, alguns presos são escolhidos e/ou se oferecem para serem espancados. Assim, extremamente feridos, eles deixam as celas, os pavilhões e a "BR" - termo que faz alusão às estradas/rodovias e como os privados de liberdade chamam os corredores superlotados - e ficam durante algum tempo na enfermaria.
} 
violentamente contidos e silenciados. Quando submetida a violento regime de exceção e brutalidade, a própria vida entra em rebelião.

\section{Cena 5: "Doutor, as 'bichas' sofrem no sistema"}

"Doutor, eu preciso falar com o senhor.É urgente." Tudo é urgente, estranho e estúpido no sistema prisional. O mesmo parece não escapar da dinâmica de funcionamento de nosso tempo onde vivemos uma espécie de urgência sem fim. Tempo estranho, como diz Stengers (2015), mas não necessariamente de estranhamentos. Tempo em que, parafraseando Símon Bolívar, há um silenciamento muito parecido com a estupidez (Galeano, 2010). Entre tantas vozes ressoando súplicas, pedidos de atenção, imperativos e interrogações, uma voz nos chama a atenção:

"Doutor, eu preciso resolver um problemão hoje. Se não resolver, vai ser babado".

Intrigado com o tal "babado", prestei uma escuta àquela "bicha preta", forma como ela mesmo se identificava. Aquela transexual fazia acompanhamento sistemático de saúde devido a uma doença infectocontagiosa. Os olhares sobre seu corpo eram parte de sua rotina na prisão. Estava privada de liberdade devido à condenação por tráfico de drogas. Ela alegava que o tráfico foi um meio de sobrevivência, pois a prostituição nas ruas não dava mais o retorno financeiro necessário para se manter, inclusive para comprar os seus hormônios. Segundo ela, a medicação para o tratamento da doença infectocontagiosa a deixava vulnerável, esquisita e se sentia ainda mais doente, o que prejudicava os seus relacionamentos amorosos, as parcerias sexuais dentro do presídio e por isso não queria mais tomar os comprimidos. Suas curvas e o seu jeito faceiro aguçavam o desejo dos outros privados de liberdade em possuí-la. Era comum muitos perguntarem se ela estava "limpa".

Aquele corpo se fazia enquanto um corpo impertinente de uma transexual preta que, ao mesmo tempo em que era odiada por afrontar a macheza do recinto, era desejada. Um corpo que recebia o abuso dos insultos, da violência física, da revista abusiva dos agentes penitenciários - os chamados baculejos - ao seu barraco e pertences. Do mesmo modo, era um corpo também alvo das intervenções dos profissionais interessados em "promover" saúde. Mais um corpo-alvo das tecnologias de cuidado que nem sempre estão preocupadas com um produzir saúde
"COM", isto é, entendendo o outro como partícipe do processo. É comum uma forma de produzir saúde "PARA", onde são ignorados os anseios, as possibilidades e as dificuldades do outro, enxergando-o como mero objeto a ser destinado um investimento de ações, quase de cunho caritativo. E, na pior das hipóteses, há também um produzir saúde "SOBRE", onde o objetivo é somente falar do outro, enquadrá-lo nas taxonomias da ciência.

Em suma, um corpo subtraído de seus direitos, um corpo matável, por ser transexual.

Dentro da prisão, este campo de concentração supostamente "humanizado", onde todos são sobreviventes tentando permanecerem vivos "até a primavera" (Levi, 1988, p. 102), uns pareciam, na hierarquia das vidas matáveis, valer menos que outros.

Pela perseguição e violências que sofreria, a transexual tinha medo de perder seus comprimidos e, pior, ter o seu agravo de saúde exposto. Com isso, busquei prestar atenção naquela história, observando os movimentos de suas mãos e seu jeito rápido de falar. Ao mesmo tempo me perguntava: $\mathrm{O}$ que pode a Psicologia aqui? O que pode um profissional com formação em Psicologia, ainda que suas atribuições sejam de apoiador institucional? A certeza que eu tinha era que a responsabilidade não se limitava a buscar suas medicações na rede de saúde, mas sim entender aquela história e respeitar seus movimentos de autonomia.

"É, doutor, as bichas sofrem no sistema. Se tiver rebelião, depois dos pedófilos, somos as primeiras a serem torturadas e mortas, o senhor sabia? É regra nos presídios daqui".

Diante da pergunta, só pude responder que não sabia e que naquele momento o que estava ao meu alcance era pensar uma forma dela cuidar da própria saúde, respeitando o seu desejo. E ao perceber a minha preocupação, disse ela: "Pode deixar doutor, eu vou me cuidar, mas vou chamar uma outra colega minha, ela também é travesti e vai me ajudar. As bichas presas daqui se apoiam, doutor. A gente só pode contar com a gente mesmo".

Após ser convocada, combinamos que a tal amiga seria a responsável por guardar a medicação longe dos olhares curiosos e dos baculejos. Construímos um código para que não faltasse a medicação. E próximo ao fim dos remédios, a amiga me encontrava e dizia:

"Doutor, tudo bem? Preciso falar com o senhor. Daqui uns 10 minutos eu volto". 
Assim, eu sabia que ainda restavam 10 comprimidos. Estratégias não convencionais num espaço também nada convencional quando o assunto é o cuidado em saúde. Mas trata-se de artimanhas, estratégias que, no cotidiano do trabalho, sem qualquer tipo de manual de como fazer, sem garantias, vamos experimentando construir um conjunto de práticas que, tanto podem mostrar-se potentes, quanto equivocadas em seus efeitos. O risco, em vários sentidos, faz parte de nosso trabalho no sistema prisional. O medo de errar, de causar um efeito deletério, faz parte do trabalho, mas não pode nos paralisar.

Face àquelas palavras, atônito com a realidade e os relatos daquela mulher transexual, percebi o quão tênue são as iniciativas para transpor as dificuldades de atuação do profissional. Aquela história fez com que eu pensasse também no ocorrido comigo na abordagem policial, dentro do ônibus. Pude sentir o quão óbvio e naturalizado é o fato de o corpo preto ser revistado fora e dentro do presídio. Que o corpo preto "trans" é ainda mais violentado e perseguido; é ainda mais corpo abjeto que os demais.

\section{Considerações finais}

No contexto da atualidade definida enquanto “estado de exceção" (Agamben, 2007), "estado de sítio global" (Arantes, 2007) ou "Estado Pós-democrático de direito" (Casara, 2017), o Estado se torna ainda "mais penal" (Wacquant, 2001) e o sistema prisional é um braço importante do projeto genocida do Estado Brasileiro (Flauzina, 2008). Ele é uma grande "fábrica de delinquentes" (Foucault, 1996) que, apesar das recorrentes críticas, das rebeliões que se faz palco, das vidas que lá são abatidas, permanece existindo e expandindo seus dispositivos, ao mesmo tempo em que novas modalidades de punir vão sendo criadas.

Nosso relato de experiência é um recorte, uma pequena pista de como funciona o sistema prisional em Pernambuco. Relato que se fez a partir do encontro de nosso corpo com a maquinaria do sistema prisional ${ }^{14}$, com todos os afetos e intensidades que tal dispositivo de captura faz circular. Ao mesmo tempo, fazendo uso de um termo da produção roteirista cinematográfica, não construímos nossa narrativa a partir da lógica da "jornada do herói” ${ }^{15}$. A narrativa clássica hollywoodiana direciona-se para um "final feliz", compondo as cenas com um misto de tensão e relaxamento, onde no fim tudo dará certo e todos poderão relaxar.

Em nosso relato, não temos certeza se as intervenções feitas foram as mais potentes; se, muitas vezes, nosso próprio trabalho pode ter sido um dispositivo de captura. Não temos um "final feliz" para contar. Nosso texto, despido da pretensão de heroísmos e supostas intervenções "fabulosas", é o compartilhamento de trajetórias e encontros; principalmente, de angústias e incertezas. Mas entendendo estas não como "afetos de tristeza" (Spinoza, 2015) a diminuir nossa potência no mundo, mas, antes, como intensidades que nos atravessam e nos provocam a pensar e a tentar construir novas estratégias de pensamento e ação.

Mais do que o relato de "experiências exitosas", de "experiências-sucesso" - e o que pode ser considerado sucesso no sistema prisional? - trazemos "experiências-faíscas", incertas, cortantes e fragmentárias que emergem para, num instante, desaparecerem. Almejamos "que do choque dessas palavras e dessas vidas ainda nos venha um certo efeito no qual se misturam beleza e assombro" (Foucault, 2003). Ao mesmo tempo, talvez nos vejamos cada dia mais vencidos, mas como aponta Pelbart (2017), a derrota tem a vantagem de nos "fazer pensar de outra maneira". Parafraseando Coimbra e Abreu (2018, p. 1102), pensar "é problematizar o que fazemos, o que somos e o mundo em que vivemos".

Não temos pretensão às generalizações, muito menos a apontar como atuar no sistema prisional. Isso não significa que "estamos à deriva", que não temos estratégias para pensar intervenções, mas que, com base nas pistas cartográficas, construímos o nosso caminhar a partir, principalmente, do território que habitamos e encontrando neste um verdadeiro canteiro de obras, cujas ferramentas que encontramos, criamos e/ou trouxemos, limites e potencialidades, fomos cartografando e aprendendo a utilizar.

Entendemos que as experiências aqui narradas têm uma potência disruptiva na medida que provocam, interrogam, duvidam e mostram um cotidiano

\footnotetext{
${ }^{14}$ Como aponta Batista (2007, p. 6), "é através do encontro com o empírico, com o conhecimento da realidade nua e crua dos nossos sistemas penais letais que poderemos reconstruir nosso saber crítico".

${ }^{15}$ Nesta, tão em voga no cinema estadunidense faz tempo, o herói (aquele em torno do qual gira a história) é convocado a ação, tentando resolver um problema, passa por adversidades, mas, no final, vence os desafios e alcança a redenção.
} 
de violência intensa. Ainda assim, o que nossos encontros nos mostram é que há, num nível complexo, para além da violência, potentes estratégias de cuidado, redes, parcerias e companheirismos que vão sendo experimentados num fio tênue entre vida e morte; amizade e luta pela sobrevivência.

Escrever sobre este território complexo que é o sistema prisional pernambucano é, para nós, uma forma de habitar a dor, as angústias e as incertezas de nossos trabalhos, bem como de nosso tempo. Tal como Coimbra e Abreu (2018), "somos afetados pela construção de um modo de pensar que faz da crítica algo mais que um soneto melancólico de lamentações". Não escrevemos para lamentar. Escrevemos para provocar, para lutar.

Por outro lado, pensamos a Psicologia, a Enfermagem, o Serviço Social, a Medicina, entre outros, como categorias que implicam em "profissionais do cuidado" (Silva, 2010) que constroem - através de um olhar atento, uma escuta sensível e um corpo aberto à experiência do encontro - um vínculo de respeito e troca que torna possível, no ambiente prisional, cuidar e ser cuidado; amparar e ser amparado. Há uma potência no exercício do cuidado que pode dar margem à invenção de processos de subjetivação singulares (Guattari, \& Rolnik, 1996).

E compreendemos o cuidado como uma estratégia micropolítica de produção de resistências; de reinvenção de si e do mundo. Ao mesmo tempo nos questionamos: Que tipo de cuidado é possível dentro de uma instituição tão mortífera? Que saúde é viável se todos ali - profissionais e privados de liberdade - vivem no fio da navalha do "esgotamento"? (Santos, 2017). Não temos respostas, mas esperamos que nosso texto seja um disparador de novos questionamentos, perguntas, dúvidas. Como diz Fulks (2016, p. 78), "o quanto do aprender a resistir não será aprender a perguntar-se?”.

\section{Referências}

Agamben, G. (2005). Infância e história: Destruição da experiência e origem da história (H. Burigo, Trad.). Belo Horizonte, MG: Editora UFMG.

Agamben, G. (2007). Estado de exceção (I. D. Poleti, Trad.). São Paulo, SP: Boitempo.

Altoé, S. (Org.). (2004). René Lourau: Analista Institucional em tempo integral. São Paulo, SP: Hucitec.

Alvarenga Filho, J. (2010). "A Chacina do Pan" e a produção de vidas descartáveis na cidade do Rio de Janeiro: "Não dá pé não tem pé nem cabeça. Não tem ninguém que mereça. não tem coração que esqueça" (dissertação de mestrado). Programa de Pós-Graduação em Psicologia da Universidade Federal Fluminense, Niterói, RJ, Brasil.

Alvarenga Filho, J. (2017). Carta a Kublai Kahn: Ou, relato de uma cidade em ebulição. In: M. Gonçalves, J. Alvarenga Filho, C. C. Cunha, \& F T. Portugal (Orgs.), Psicologia, direitos humanos e movimentos sociais: Capturas e insurgências na cidade (Coleção Encontro em Psicologia, Vol. 3, pp. 29-41). Porto Alegre, RS: Abrapso.

Alvarez, J., \& Passos, E. (2009). Cartograr é habitar um território existencial. In: E. Passos, V. Kastrup, \& L. da Escóssia, (Orgs.), Pistas do método da cartografia: Pesquisa-intervenção e produção de subjetividade (pp. 132-150). Porto Alegre, RS: Sulina.

Anzaldúa, G. (2000). Falando em línguas: Uma carta para as mulheres escritoras do Terceiro Mundo. Revista Estudos Feministas, 8(1), 229-236.

Arantes, P. (2007). Extinção. São Paulo, SP: Boitempo.

Artières, P. (2004). Dizer a atualidade: O trabalho diagnóstico em Michel Foucault. In: F. Gross (Org.), Foucault a coragem da verdade (M. Marciolino, Trad.). São Paulo, SP: Parábola.

Artières, P., Bert, J. F., Gros, F., \& Revel, J. (2011). Michel Foucault. São Paulo, SP: Forense Universitária.

Augusto, A. (2010). Para além da prisão-prédio: As periferias como campos de concentração a céu aberto. Cadernos Metropolis, 12(23), 263-276. https://doi.org/10.1590/5933

Baptista, L. A. S. (2001). A fábrica de interiores. Niterói, RJ: Editora Universidade Federal Fluminense.

Baremblitt, G. F. (2002) Compêndio de análise institucional e outras correntes: teoria e prática (5a ed.). Belo Horizonte, MG: Instituto Felix Guattari. 
Psicologia: Ciência e Profissão 2018 v. 38 (núm. esp.2), 117-130.

Batista, N. (1990). Punidos e mal pagos. Rio de Janeiro, RJ: Revan.

Batista, N. (2003). Mídia e sistema penal no capitalismo tardio. Revista Brasileira de Ciências Criminais, (43), 1-20.

Batista, V. M. (2007). O realismo marginal: Criminologia, sociologia e história. São Paulo, SP: Observatório das Violências Policiais SP.

Batista, V. M. (2017). Prefácio. In: C. Rauter, O medo do crime no Brasil: Controle social e rebelião. Rio de Janeiro, RJ: E-Papers.

Benevides, R. (2013). Grupo: A afirmação de um simulacro. Porto Alegre, RS: Sulina.

Bondía, J. (2002). Notas sobre a experiência e o saber de experiência. Revista Brasileira de Educação, (19), 20-28. https://doi.org/10.1590/S1413-24782002000100003

Bondía, J. (2003). O ensaio e a escrita acadêmica. Educação \& Realidade, 28(2), 101-115.

Brasil. Ministério da Saúde. Secretaria de Atenção à Saúde. (2010). Política Nacional de Humanização. Formação e intervenção. Brasília, DF: o autor.

Brasil. Ministério da Justiça e Segurança Pública. (2017). Levantamento Nacional de Informações Penitenciárias: INFOPEN Atualização Junho de 2016. Brasília, DF: o autor. Recuperado de http:// depen.gov.br/DEPEN/depen/ sisdepen/infopen/infopen

Brum, E. (2006). A vida que ninguém vê. Porto Alegre, RS: Arquipélago.

Casara, R. (2017). Estado pós-democrático: Neo-obscurantismo e gestão dos indesejáveis. Rio de Janeiro, RJ: Civilização Brasileira.

Coimbra, C. (1995). Guardiães da ordem: Uma viagem pelas práticas psi no Brasil do "Milagre". Rio de Janeiro, RJ: Oficina do Autor.

Coimbra, C., \& Abreu, A. (2018). 1968 na França - 2013 no Brasil: Acontecimentos-Resistências. Revista Direito e Práxis, 9(2), 1100-1121. https:// doi.org/10.1590/2179-8966/2018/34074

Costa, L. A., Angeli, A. A. C., \& Fonseca, T. M. G. (2012). Cartografar. In: T. M. G. Fonseca, M. L. Nascimento, \& C. Maraschin. (Orgs.), Pesquisar na Diferença: Um abecedário (pp. 43-46). Porto Alegre, RS: Editora Sulina.

Costa, L. B. (2014). Cartografia: Uma outra forma de pesquisar. Revista Digital do LAV, 7(2), 66-77. http://dx.doi. org/10.5902/1983734815111

Decotteli, K., Bohre, L., \& Bicalho. P. (2013). A droga da obediência: Medicalização, infância e biopoder: Notas sobre clínica e política. Psicologia: Ciência e Profissão, 33(2), 446-459. https://doi.org/10.1590/S141498932013000200014

Drummond, C. (2010). Uma pedra no meio do caminho. Rio de Janeiro, RJ: IMS.

Fanon, F. (2008). Pele negra, máscaras brancas (R. Silveira, Trad.). Salvador, BA: EdUFBA.

Flauzina, A. L. P. (2008). Corpo negro caído no chão: O sistema penal e projeto genocida do Estado brasileiro. Rio de Janeiro, RJ: Contraponto.

Fonseca, T. M. G., Kirst, P. G., Oliveira, A. M., D’Ávila, M. F., \& Marsilac, A. L. M. (2006). Pesquisa e acontecimento: O toque no impensado. Psicologia em Estudo, 11(3), 655-660. https://dx.doi.org/10.1590/S1413-73722006000300022

Foucault, M. (2003). A vida dos homens infames. In: M. B. Motta (Ed.), Estratégia, poder-saber (pp. 203-222). Rio de Janeiro, RJ: Forense Universitária.

Foucault, M. (2010). Conversa com Michel Foucault. In: M. Foucault. Ditos e escritos (Vol. 6: Repensar a política, pp. 289-347). Rio de Janeiro, RJ: Forense Universitária.

Foucault, M. (1998). História da sexualidade II: O uso dos prazeres (M. T. C. Albuquerque, Trad.). São Paulo, SP: Paz e Terra.

Foucault, M. (2008). O nascimento da biopolítica (E. Brandão, Trad.). São Paulo, SP: Martins Fontes.

Foucault, M. (1996). Vigiar e punir (R. Ramalhete, Trad.). Petrópolis, RJ: Vozes.

Fulks, J. (2016). A resistência. São Paulo, SP: Companhia das Letras.

Galeano, E. (2010). As veias abertas da América Latina (S. Faraco, Trad.). Porto Alegre: LM \&P Pocket. 
Guattari, F, \& Rolnik, S. (1996). Micropolítica: Cartografias do desejo. Petrópolis, RJ: Vozes.

Lei No 7.210, de 11 de julho de 1984. Institui a Lei de Execução Penal. Diário Oficial da União. 13 jul. 1984.

Leite, M. P. V. (2014). Cartografar (n)a prisão. Estudos e Pesquisas em Psicologia, 14(3), 795-813.

Levi, P. (1988). É isso um homem? (L. Del Re, Trad.). São Paulo, SP: Rocco.

Lourau, R. (1993) Análise Institucional e práticas de pesquisa. Rio de Janeiro, RJ: EdUERJ.

Machado, L. A. D. (2004). O desafio ético da escrita. Psicologia \& Sociedade, 16(1), 146-150. https://doi.org/10.1590/ S0102-71822004000100012

Merhy, E. (2004). Cuidado com o cuidado em saúde: Saiba explorar seus paradoxos para defender a vida: o ato de cuidar é um ato paradoxal: Pode aprisionar ou liberar. Campinas, SP: UFF.BR.

Nietzsche, F. (2017). Crepúsculo dos ídolos (P. C. Souza, Trad.). São Paulo, SP: Companhia de Bolsa.

Pelbart. P. (2017). Estamos em guerra. Outras palavras; comunicação compartilhada e pós capitalismo. São Paulo, SP: Outras Palavras. Recuperado de https:// outraspalavras.net/brasil/peter-pal-pelbart-estamos-em-guerra/.

Prado Filho, K., \& Trisotto, S. (2007). A psicologia como disciplina da norma. Revista Aulas, 1(3), 1-14. Recuperado de https://www.ifch.unicamp.br/ojs/index.php/aulas/article/view/1943/1404.

Ribeiro, D. (2015). O povo brasileiro. Rio de Janeiro, RJ: Global.

Rolnik, S. (1989). Cartografia ou de como pensar com o corpo vibrátil: Trechos de cartografia sentimental, transformações contemporâneas do desejo. São Paulo, SP: Estação Liberdade. Recuperado de http://www.pucsp.br/ nucleodesubjetividade/Textos/SUELY/pensarvibratil.pdf

Santos, A. R. C. (2017). Destituição, esgotamento, criação. In: M. A. Gonçalves, J. R. Alvarenga Filho, C. C. Cunha, \& F. T. Portugal (Orgs.), Psicologia, direitos humanos e movimentos sociais: Capturas e insurgências na cidade (Coleção Encontro em Psicologia, Vol. 3, pp. 93-106). Porto Alegre, RS: Abrapso.

Santos, J. (2004). Épuras do social: Como podem os intelectuais trabalhar para os pobres. São Paulo, SP: Global.

Silva, A. (2010). Cenários e desafios da práxis psicológica no sistema prisional: Ética e compromisso social. In: Conselho Federal de Psicologia - CFP (Org.), A atuação do psicólogo no sistema prisional. Brasília, DF: o autor.

Spinoza, B. (2015). Ética (Grupo de Estudos Espinosianos, Trad. Coletiva). São Paulo, SP: EdUSP.

Stengers, I. (2015). No tempo das catástrofes (E. Araujo, Trad.). São Paulo, SP: Cosac Naify.

Tamis, P. (2018). Eu preta, pobre, crakeira. São Paulo, SP: Geledes.

Valois, L. C. (2016). Polícia social: A uniformização de um comportamento moral. In: L. C. Valois, O Direito penal da guerra às drogas (2a ed.). Belo Horizonte: D’Plácido.

Wacquant, L. (2001). As prisões da miséria. Rio de Janeiro, RJ: J. Zahar.

\section{Antonio Lima}

Graduado em Psicologia pela Universidade Federal Fluminense (UFF), Niterói - RJ. Brasil. Especialista em Saúde da Família pelo Programa de Residência Multiprofissional em Saúde da Família da Escola Nacional de Saúde Pública Sérgio Arouca da Fundação Oswaldo Cruz (ENSP/Fiocruz), Rio de Janeiro - RJ. Brasil. Mestrando do Programa de Pós-Graduação em Saúde Pública pelo Instituto Aggeu Magalhães da Fundação Oswaldo Cruz (IAM/Fiocruz-PE), Recife - PE. Brasil.

E-mail: antoniolimapsi@gmail.com

(iD https:// orcid.org/0000-0001-6308-6532

José Rodrigues de Alvarenga Filho

Docente do Departamento de Psicologia da Universidade Federal de São João del-Rei (UFSJ-MG), São João del-Rei - MG. Brasil.

E-mail: joserodrigues@ufsj.edu.br

(iD) https:// orcid.org/0000-0002-6145-8491 
Endereço para envio de correspondência:

Fundação Oswaldo Cruz (Fiocruz) - Pernambuco

Instituto Aggeu Magalhães (IAM)

Av. Professor Moraes Rego, S/n - Campus UFPE

CEP. 50740465

Cidade Universitária - Recife-PE

Recebido 16/08/2018

Aprovado 23/08/2018

Received 08/16/2018

Approved 08/23/2018

Recibido 16/08/2018

Aceptado 23/08/2018

Como citar: Lima, A., \& Alvarenga Filho, J. R. (2018). A potência do cuidado: Uma experiência no sistema prisional de Pernambuco. Psicologia: Ciência e Profissão, 38(n.spe.2), 117-130. https://doi.org/10.1590/1982-3703000211971

How to cite: Lima, A., \& Alvarenga Filho, J. R. (2018). The potency of care: an experience in the prision system of Pernambuco. Psicologia: Ciência e Profissão, 38(n.spe.2), 117-130. https://doi.org/10.1590/1982-3703000211971

Cómo citar: Lima, A., \& Alvarenga Filho, J. R. (2018). La Potencia del Cuidado: una Experiencia en el Sistema Penitenciario de Pernambuco. Psicologia: Ciência e Profissão, 38(n.spe.2), 117-130. https://doi.org/10.1590/1982-3703000211971 